\title{
Increased Risk of Humeral Fracture With Open Versus Arthroscopic Tenodesis of the Long Head of the Biceps Brachii
}

\author{
Robert L. Parisien, M.D., David P. Trofa, M.D., H. P. Kang, M.D., Hasani W. Swindell, M.D., \\ Nicholas Trasolini, M.D., Xinning Li, M.D., and Christopher S. Ahmad, M.D.
}

\begin{abstract}
Purpose: To determine the risk of postoperative humeral fracture following tenotomy, open tenodesis and arthroscopic tenodesis of the long head of the biceps brachii. Methods: A retrospective review of deidentified patient data from the Medicare Standard Analytic File using the PearlDiver software was conducted to identify procedures performed between 2005 and 2014. Groups were matched by age, gender, region, and medical comorbidities. Results: We evaluated 157,163 patients who had undergone arthroscopic or open tenodesis or tenotomy of the long head of the biceps brachii over a 10year period (2005-2014), and we identified 2,196 postoperative humeral fractures (1.4\%). Matched subgroup analysis consisting of 44,292 patients demonstrated a statistically significant increase in humeral fracture risk in open (280; $1.26 \%$ ) compared to arthroscopic tenodesis $(232 ; 1.04 \%)$ with a $P$ value of 0.03 and an odds ratio of 1.21 . The majority of fractures were sustained by patients 65-74 years of age. Conclusion: In this study, an increased risk of postoperative humeral fracture was associated with open tenodesis of the LHB. Level of Evidence: III, Retrospective Comparative Trial.
\end{abstract}

$\mathbf{T}$ he long head of the biceps brachii (LHB) tendon is considered a significant source of anterior shoulder pain and may present in isolation or in association with concomitant extra- and intra-articular shoulder pathology. Factors supporting surgical management of LHB pathology include a symptomatic clinical examination with provocative testing, concomitant shoulder pathology, refractory nonsurgical management, symptomatic partial-thickness tear, medial subluxation,

From the Department of Orthopaedic Surgery, University of Pennsylvania (R.L.P.), Philadelphia, Pennsylvania; Department of Orthopaedic Surgery, Columbia University Medical Center (D.P.T., H.W.S., C.S.A.), New York, New York; Department of Orthopaedic Surgery, Keck School of Medicine, University of Southern California (H.P.K., N.T.), Los Angeles, California; Department of Orthopaedic Surgery Boston University School of Medicine and Medical Center (X.L.), Boston, Massachusetts, U.S.A.

The authors report no conflicts of interest in the authorship and publication of this article. Full ICMJE author disclosure forms are available for this article online, as supplementary material.

Received October 23, 2019; accepted April 21, 2020.

Address correspondence to Robert L. Parisien, M.D., Department of Orthopaedic Surgery, University of Pennsylvania, Penn Sports Medicine Center, 235 South 33rd Street, Philadelphia, PA 19104, U.S.A. E-mail: Robert.L. Parisien@gmail.com

(C) 2020 THE AUTHORS. Published by Elsevier Inc. on behalf of the Arthroscopy Association of North America. This is an open access article under the CC BY-NC-ND license (http://creativecommons.org/licenses/by-nc-nd/4.0/).

2666-061X/191277

https://doi.org/10.1016/j.asmr.2020.04.010 symptomatic SLAP tear, and presence of intraoperative erythema, vascular injection, or "lipstick" tendon lesion, with hypertrophy. ${ }^{1-6}$ However, controversy remains with regard to the optimal surgical management of LHB pathology; tenotomy and tenodesis represent the 2 most popular procedures. Biceps tenotomy is typically performed arthroscopically and is thought to relieve pain via the elimination of traction stress, but it is limited by an increased incidence of postoperative cosmetic "popeye" deformity, fatigue, discomfort, and cramping in the biceps muscle belly. ${ }^{7-10}$ On the other hand, tenodesis involves the placement of additional hardware, which increases the risk of neurologic injury. ${ }^{7,9}$ However, there remains significant controversy surrounding the appropriate method and location of tenodesis and open versus arthroscopic, and several studies seem to be at odds with each other. ${ }^{11-13}$

An enduring argument that appears to be in favor of tenotomy has been the theoretical increased risk of postoperative humeral fracture associated with open tenodesis. However, the existing literature offers relatively sparse supporting data; the studies lack statistical power. The purpose of this evaluation was to determine the risk of postoperative humeral fracture following tenotomy, open tenodesis and arthroscopic tenodesis of the LHB. We hypothesized a greater incidence of postoperative humeral fractures with tenodesis versus tenotomy as well as with open versus arthroscopic tenodesis of the LHB. 
Table 1. Age-, Gender-, Regional-, and CormobidityMatched Tenotomy versus Tenodesis Group Characteristics

\begin{tabular}{lc}
\hline \multicolumn{1}{c}{ Characteristics } & $\mathrm{N}$ \\
\hline Age & 11,036 \\
$\leq 64$ & 19,188 \\
$65-69$ & 13104 \\
$70-74$ & 7,175 \\
$75-79$ & 2,514 \\
$80-84$ & 576 \\
$\geq 85$ & 491 \\
Unknown & \\
Gender & \\
Female & 23,778 \\
Male & 29,815 \\
Unknown & 491 \\
Region & \\
Midwest & 12,844 \\
Northeast & 7957 \\
South & 22,011 \\
West & 9,523 \\
Unknown & 1,749 \\
Elixhauser Comorbidity Index ${ }^{14}$ & $5.84 \pm 3.93$ \\
Total & 54,084 \\
\hline
\end{tabular}

\section{Methods}

Deidentified patient data from the Medicare Standard Analytic File was queried using PearlDiver software (PearlDiver, Colorado Springs, CO), and a retrospective review was conducted from January 2005 through December 2014. Procedures were identified using Current Procedural Terminology (CPT) codes, whereas humerus fractures were identified using International Classification of Diseases, 9th revision (ICD-9) codes.

All patients undergoing tenodesis were identified using CPT-29828 and CPT-23439. Similarly, patients undergoing tenotomy were identified as CPT-23405 as well as CPT-29822. We excluded patients with histories of shoulder arthroplasty or hemiarthroplasty, identified by their relevant CPT codes, as well as patients who had previously sustained humeral fractures, as identified by ICD-9 codes.

After identifying the study populations and postoperative humerus fracture rates, we refined our analysis by creating matched groups. The tenodesis and tenotomy groups were matched by age, gender, region, and medical comorbidities as quantified by the Elixhauser Comorbidity Index ${ }^{14}$ (Table 1). Postoperative fractures were then analyzed to investigate differences between these groups. Last, a matched subgroup analysis was performed within the tenodesis group to compare fracture risk of open versus arthroscopic techniques (Table 2).

\section{Statistical Analysis}

An a priori significance was set at an alpha of 0.05 . Age, gender and regional differences in distribution among groups were compared using the KolmogorvSmirnov test. The Elixhauser Comorbidity Index ${ }^{14}$ was compared using a 2-tailed Student $t$ test. Fracture rates were compared using odds ratios calculated in the standard fashion. Statistical tests were performed using Microsoft Excel (Microsoft, Redmond, WA) and SPSS (IBM Analytics, Armonk, NY).

\section{Results}

Over a 10-year period (2005-2014), we evaluated 157,163 patients having undergone an arthroscopic or open tenodesis or tenotomy of the LHB and identified 2,196 postoperative humeral fractures $(1.4 \%)$. To control for confounding variables and to increase study efficiency, matched tenodesis and tenotomy groups were further analyzed with regard to gender, age, comorbidities, and geographic region, which yielded 2 groups including 54,084 patients. No statistical difference was demonstrated in the risk of humeral fracture in the tenodesis group $(643,1.19 \%)$ as compared to the tenotomy group $(698,1.29 \%) ; P 0.13$. Humeral fracture data was further evaluated at 1-, 3-, 6- and 12-month intervals, yielding no significant differences between the tenodesis and tenotomy groups at any given time-point. The majority of fractures that were sustained, thus demonstrating the greatest risk, occurred in patients 65-74 years of age. Additional matched subgroup analysis consisting of a total of 44,292 patients demonstrated a statistically significant increase in humeral fracture risk in open $(280,1.26 \%)$ compared to arthroscopic tenodesis $(232,1.04 \%)$ with a $P$ value of 0.03 and an odds ratio of 1.21 .

\section{Discussion}

In our current evaluation of more than 150,000 patients appropriately matched to limit confounder bias, the data demonstrate a statistically significant difference favoring arthroscopic versus open tenodesis with regard to postoperative fracture risk. We report a $1.26 \%$ incidence of humeral fracture with open tenodesis versus a $1.04 \%$ risk with arthroscopic techniques. Additionally, the overall incidence of humeral fracture following tenodesis or tenotomy is relatively uncommon, at $1.4 \%$, with the majority of fractures occurring in patients 65-74 years of age. The published literature consists of numerous primary studies and systematic reviews that demonstrate no, or only minimal, differences in head-to-head evaluation of tenotomy versus tenodesis; only a few studies report data regarding humeral fracture risk. ${ }^{15-19}$

Table 2. Fracture Comparison for Matched Open Versus Arthroscopic Tenodesis Groups

\begin{tabular}{lcccc}
\hline & Open & Arthroscopic & OR & $P$ value \\
\hline Group & 22,146 & 22,146 & & \\
Fracture & $280(1.26 \%)$ & $232(1.06 \%)$ & 1.21 & 0.03 \\
\hline
\end{tabular}


Frost et al. ${ }^{15}$ performed a comprehensive quantitative review comparing outcomes of LHB tenotomy versus tenodesis and concluded that "there is a lack of quality evidence to advocate one technique over the other." They recommended the performance of additional randomized control trials. In a prospective evaluation of 20 patients, Hufeland et al. ${ }^{16}$ were unable to find any significant difference but reported a trend toward increased rate of popeye deformity following biceps tenotomy. Slenker et al. ${ }^{18}$ came to the same conclusion following their systematic review of the literature. The only difference they reported was a higher incidence of cosmetic deformity with biceps tenotomy and concluded that there is "no consensus regarding the use of tenotomy versus tenodesis." An additional comprehensive review by Hsu et al. ${ }^{19}$ came to the same conclusion regarding increased incidence of cosmetic deformity following tenotomy as compared to tenodesis. Consistent with other reports and analyses, they reported there is "no consensus in the literature regarding the use of tenotomy versus tenodesis for LHB tendon lesions due to variable results." However, these published studies failed to evaluate and report on the rate of humeral fracture as a complication of LHB tenotomy compared to tenodesis so, prior to our study, this risk remained unknown. Our study provides evidence, with evaluation of matched groups of more than 100,000 patients, demonstrating no difference in humeral fracture risk when comparing LHB tenotomy to tenodesis.

However, several published biomechanical reports and case series have described the risk of humeral fracture specifically following tenodesis of the LHB. A biomechanical study of 10 matched human humeri by Euler et al. $^{20}$ attempted to provide evidence for the etiology of humeral fracture following tenodesis of the LHB. They demonstrated a $25 \%$ decreased humeral load due to failure of an eccentrically placed $8 \mathrm{~mm}$ tenodesis screw and suggested that concentrically placed smaller screws or other techniques be considered to decrease the risk of humeral fracture. A recent biomechanical analysis further compared 14 full-length matched humeri and found similar results. Torsional load to humeral fracture was reduced $20 \%, 28 \%$ and $30 \%$ in the evaluation of both screw and biceps placement, $8 \mathrm{~mm}$ unicortical hole alone and placement of PEEK tenodesis screw alone, respectively. ${ }^{21}$ These studies demonstrate a real biomechanical risk of humeral fracture, a devastating complication of biceps tenodesis, when using larger interference screw fixation. Only a few evaluations of such complications have been published in the literature, although we suspect this to be significantly under-reported. ${ }^{22,23}$ Dein et al. ${ }^{22}$ describe an episode of humeral fracture in a 46-yearold pitcher in an adult baseball league following biceps tenodesis using an interference screw. Additionally, Reiff et al. ${ }^{24}$ reported this devastating complication in a 50-year-old woman following open tenodesis of the
LHB, and there are additional reports of humeral fracture resulting from the "keyhole technique," originally described by Froimson in 1975. ${ }^{24-27}$

Given this apparent risk, we sought to investigate the difference through direct comparison of open versus arthroscopic tenodesis. There are numerous studies comparing the complications resulting from these 2 particular procedures; however, these published reports and reviews remain significantly underpowered to demonstrate a statistical difference and are, thus, prone to type II error. Gombera et al. ${ }^{13}$ evaluated allarthroscopic suprapectoral versus open subpectoral tenodesis of the LHB and reported no difference in American Shoulder and Elbow Surgeons (ASES) scores and patient satisfaction. There were no complications in the all-arthroscopic group and only 2 in the open subpectoral group, which were resolved by final follow-up. However, this study evaluated only 2 groups of 23 patients. Yi et al. ${ }^{28}$ investigated the effect of arthroscopic versus open subpectoral tenodesis of the LHB in conjunction with repair of small and medium-sized rotator cuff tears. There was no difference in range of motion, ASES or Constant-Murley scores in a comparison of only 34 versus 32 cases. Additionally, a comparison of functional outcomes of open versus arthroscopic biceps tenodesis was performed by Duchman et al. ${ }^{11}$ They reported no difference in range of motion, strength, Short Form Health Survey (SF-36) results and ASES scores. Again, they evaluated only 25 open versus 20 arthroscopic tenodeses and did not look at fracture risk. The authors concluded that future studies are warranted to "determine if discrete patient populations are better served by either open or arthroscopic LHB tenodesis techniques." Perhaps the largest analysis in the pre-existing literature consists of 598 patients via a systematic review of 7 clinical trials. ${ }^{29}$ The authors concluded that there was no difference with regard to patient satisfaction, return to sport or ASES and Constant-Murley scores.

\section{Limitations}

Despite these compelling data, we must address the inherent limitations of our evaluation, given the retrospective study design of a national Medicare database. Furthermore, all retrospective studies are intrinsically biased by our inability to discern patterns in random noise. After noticing such patterns, researchers pursue formal data analysis, which subsequently confirms the pattern, thus introducing potential retrospective bias. In addition, given the decreased power of previous investigations, they are subject to type II $\beta$ error by stating no difference where 1 may truly exist. Given our substantial group of $>150,000$ patients, we attempted to decrease significantly our susceptibility to such error and bias. By creating age, sex, comorbid, and regionally matched groups, we further attempted to increase homogeneity so as to 
identify and analyze accurately the appropriate groups. Despite these efforts, data extracted via PearlDiver software is only as good as the quality of data input. As such, we were limited by the fact that data regarding specific tenodesis technique, implant use and fracture location (proximal versus distal) were not available via the Medicare Standard Analytic File.

\section{Conclusions}

In this study, an increased risk of postoperative humeral fracture was associated with open tenodesis of the LHB

\section{References}

1. Ahrens PM, Boileau P. The long head of biceps and associated tendinopathy. J Bone Joint Surg Br 2007;89: $1001-1009$.

2. Sethi N, Wright R, Yamaguchi K. Disorders of the long head of the biceps tendon. J Shoulder Elbow Surg 1999;8: 644-654.

3. Barber FA, Byrd JW, Wolf EM, Burkhart SS. How would you treat the partially torn biceps tendon? Arthroscopy $2001 ; 17: 636-639$.

4. Franceschi F, Longo UG, Ruzzini L, Rizzello G, Maffulli N, Denaro V. No advantages in repairing a type II superior labrum anterior and posterior (SLAP) lesion when associated with rotator cuff repair in patients over age 50: A randomized controlled trial. Am J Sports Med 2008;36:247-253.

5. Mazzocca AD, Rios CG, Romeo AA, Arciero RA. Subpectoral biceps tenodesis with interference screw fixation. Arthroscopy 2005;21:896.

6. Boileau P, Ahrens PM, Hatzidakis AM. Entrapment of the long head of the biceps tendon: The hourglass biceps: A cause of pain and locking of the shoulder. J Shoulder Elbow Surg 2004;13:249-257.

7. De Carli A, Vadalà A, Zanzotto E, Zampar G, Vetrano M, Iorio R, Ferretti A. Reparable rotator cuff tears with concomitant long-head biceps lesions: Tenotomy or tenodesis? Knee Surg Sports Traumatol Arthrosc 2012;20: 2553-2558.

8. Sentürk I, Ozalay M, Akpınar S, Leblebici B, Cınar BM, Tuncay C. Clinical and isokinetic comparison between tenotomy and tenodesis in biceps pathologies. Acta Orthop Traumatol Turc 2011;45:41-46.

9. Zhang Q, Zhou J, Ge H, Cheng B. Tenotomy or tenodesis for long head biceps lesions in shoulders with reparable rotator cuff tears: a prospective randomised trial. Knee Surg Sports Traumatol Arthrosc 2015:23:464-469.

10. Kelly AM, Drakos MC, Fealy S, Taylor SA, O’Brien SJ. Arthroscopic release of the long head of the biceps tendon: Functional outcome and clinical results. Am J Sports Med 2005;33:208-213.

11. Duchman KR, DeMik DE, Uribe B, Wolf BR, Bollier M. Open versus arthroscopic biceps tenodesis: A comparison of functional outcomes. Iowa Orthop 2016;36:79-87.

12. Mardani-Kivi M, Keyhani S, Ebrahim-Zadeh MH, Hashemi-Motlagh K, Saheb-Ekhtiari K. Rotator cuff tear with concomitant long head of biceps tendon (LHBT) degeneration: What is the preferred choice? Open subpectoral versus arthroscopic intraarticular tenodesis. J Orthop Traumatol 2019 5;20:26.

13. Gombera MM, Kahlenberg CA, Nair R, Saltzman MD, Terry MA. All-arthroscopic suprapectoral versus open subpectoral tenodesis of the long head of the biceps brachii. Am J Sports Med 2015;43:1077-1083.

14. Elixhauser A, Steiner C, Harris DR, Coffey RM. Comorbidity measures for use with administrative data. Med Care 1998;36:8-27.

15. Frost A, Zafar MS, Maffulli N. Tenotomy versus tenodesis in the management of pathologic lesions of the tendon of the long head of the biceps brachii. Am J Sports Med 2009;37:828-833.

16. Hufeland M, Wicke S, Verde PE, Krauspe R, Patzer T. Biceps tenodesis versus tenotomy in isolated LHB lesions: A prospective randomized clinical trial. Arch Orthop Trauma Surg 2019;139:961-970.

17. Boileau P, Baqué F, Valerio L, Ahrens P, Chuinard C, Trojani C. Isolated arthroscopic bicep tenotomy or tenodesis improves symptoms in patients with massive irreparable rotator cuff tears. J Bone Joint Surg Am 2007;89:747-757.

18. Slenker NR, Lawson K, Ciccotti MG, Dodson CC, Cohen SB. Biceps tenotomy versus tenodesis: Clinical outcomes. Arthroscopy 2012;28:576-582.

19. Hsu AR, Ghodadra NS, Provencher MT, Lewis PB, Bach BR. Biceps tenotomy versus tenodesis: A review of clinical outcomes and biomechanical results. J ShoulderElbow Surg 201 1;20:326-332.

20. Euler SA, Smith SD, Williams BT, Dornan GJ, Millett PJ, Wijdicks CA. Biomechanical analysis of subpectoral biceps tenodesis: Effect of screw malpositioning on proximal humeral strength. Am J Sports Med 2015;43:69-74.

21. Mellano CR, Frank RM, Shin JJ, et al. Subpectoral Biceps Tenodesis With PEEK Interference Screw: A biomechanical analysis of humeral fracture risk. Arthroscopy 2018;34: 806-813.

22. Dein EJ, Huri G, Gordon JC, McFarland EG. A humerus fracture in a baseball pitcher after biceps tenodesis. Am J Sports Med 2014;42:877-879.

23. Sears BW, Spencer EE, Getz CL. Humeral fracture following subpectoral biceps tenodesis in 2 active, healthy patients. J Shoulder Elbow Surg 2011;20:e7-el1.

24. Reiff SN, Nho SJ, Romeo AA. Proximal humerus fracture after keyhole biceps tenodesis. Am J Orthop (Belle Mead, NJ) 2010;39:E61-63.

25. Froimson A. Keyhole tenodesis of biceps origin at the shoulder. Clin Orthop Relat Res 1975;112:245-249.

26. Gyulai M. Humeral fracture after keyhole tenodesis. Magy Traumatol Orthop Helyreallito Seb 1990;33:234-236.

27. Friedel R, Markgraf E, Schmidt I, Donicke T. Proximal humarus shaft fracture as a complication after keyholeplasty: A case report. Unfallchirurgie 1995;21:198-201.

28. Yi Y, Lee JM, Kwon SH, Kim JW. Arthroscopic proximal versus open subpectoral biceps tenodesis with arthroscopic repair of small- or medium-sized rotator cuff tears. Knee Surg Sports Traumatol Arthrosc 2016;24:3772-3778.

29. Hurley DJ, Hurley ET, Pauzenberger L, Lim Fat D, Mullett H. Open compared with arthroscopic biceps tenodesis: A systematic review. JBJS Rev 2019;7:e4. 